\title{
Colorectal cancer screening in Europe: differences in approach; similar barriers to overcome
}

\author{
Nicholas J. West • Christian Boustière • \\ Wolfgang Fischbach $\cdot$ Fabrizio Parente • \\ Roger J. Leicester
}

Published online: 2 July 2009

(C) Springer-Verlag 2009

\section{Erratum to: Int J Colorectal Dis \\ DOI 10.1007/s00384-009-0690-6}

The section 'The Lecco colorectal cancer screening programme' and Table 4 have incorrect data. The highlighted areas of text specifically are the corrections.

\section{The Lecco colorectal cancer screening program}

The programme has been organised in this pilot area (one of the eleven provinces of Lombardy) according to the schedule of conditions defined by Regional Health Authorities. It commenced in February 2006 using faecal occult blood

The online version of the original article can be found at http://dx.doi. org/10.1007/s00384-009-0690-6.

N. J. West ( $₫)$

Endoscopy Department, St George's Hospital,

London, UK

e-mail: nwest@sgul.ac.uk

C. Boustière

Gastrointestinal, Endoscopic Unit, St Joseph Hospital,

Marseilles, France

W. Fischbach

Internal Medicine, Academic Teaching Hospital,

University of Würzburg,

Würzburg, Germany

F. Parente

Gastroenterology, A. Manzoni Hospital,

Lecco, Italy

R. J. Leicester

Endoscopy Department, St George's Hospital,

Blackshaw Road,

London SW17 OQT, UK testing every two years in the target population followed by total colonoscopy in FOBT-positive individuals.

The target population for screening comprises 80,915 men and women aged between 50 and 69 years resident in the Province. Criteria for exclusion are: history of colorectal adenoma or cancer, known inflammatory colonic disease and recent, (within 3 years) well-documented complete colonoscopy.

For the period 2006-2008:

- 78, 083 invitations were sent out regionally

- 38,693 returned, i.e. $49.6 \%$ compliance

- 2,392 positive FOBT (6.2\%)

- 2,231 eligible for colonoscopy (93.3\%)

- 2,052 colonoscopies (92\%)

- $876(42.7 \%)$ adenomatous polyps

- $95(4.6 \%)$ cancers detected 


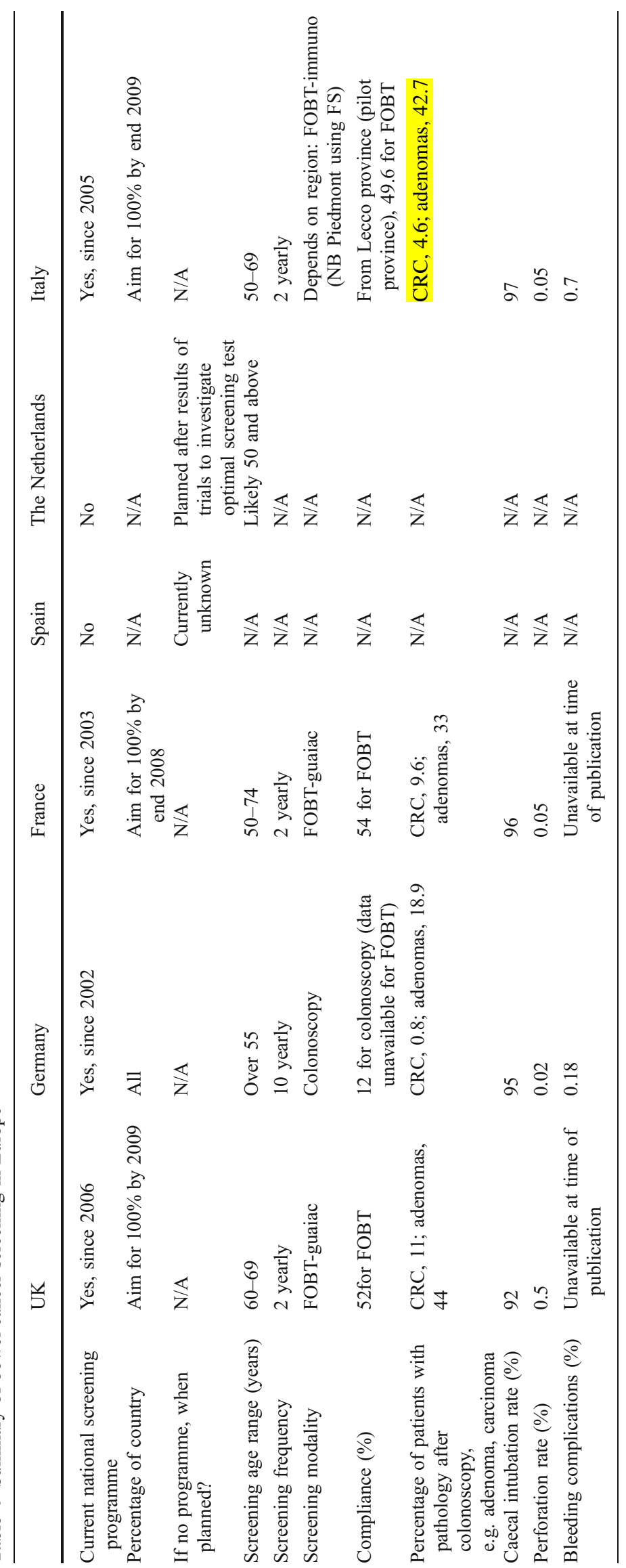

